\title{
Synthesis, Crystal Structure and Thermal Behavior of a 3-D Barium(II)/Iron(III)-Oxalate Polymer
}

\author{
Noé Makon Ma Houga1, Brian S. Dolinar², Justin Nenwa ${ }^{1 *}$, Gouet Bebga ${ }^{3}$ \\ ${ }^{1}$ Department of Inorganic Chemistry, University of Yaounde 1, Yaounde, Cameroon \\ ${ }^{2} 2124$ Chemistry Department, University of Wisconsin-Madison, Madison, USA \\ ${ }^{3}$ Department of Chemistry, Higher Teacher Training College, University of Yaounde 1, Yaounde, Cameroon \\ Email: ${ }^{*}$ inenwa@yahoo.fr
}

Received 14 January 2014; revised 21 February 2014; accepted 2 March 2014

Copyright (C) 2014 by authors and Scientific Research Publishing Inc.

This work is licensed under the Creative Commons Attribution International License (CC BY). http://creativecommons.org/licenses/by/4.0/

(c) (i) Open Access

\section{Abstract}

Reaction of $\mathrm{Ba}\left(\mathrm{NO}_{3}\right)_{2}$ with $\mathrm{Fe}\left(\mathrm{NO}_{3}\right)_{3} \cdot 9 \mathrm{H}_{2} \mathrm{O}$ and $\mathrm{H}_{2} \mathrm{C}_{2} \mathrm{O}_{4} \cdot 2 \mathrm{H}_{2} \mathrm{O}$ in aqueous medium readily affords, in high yield, the bimetallic complex polymer of chemical composition $\left\{\mathrm{Ba}_{6}\left(\mathrm{H}_{2} \mathrm{O}\right)_{17}\left[\mathrm{Fe}\left(\mathrm{C}_{2} \mathrm{O}_{4}\right)_{3}\right]_{4}\right\} \cdot 7 \mathrm{H}_{2} \mathrm{O}$ (1), consistent with the expected ratio of $3 \mathrm{Ba}^{\mathrm{II}} \mathrm{vs}$. $2 \mathrm{Fe}^{\mathrm{III}}$. Compound 1 was fully characterized by elemental and thermal analyses, vibrational FTIR spectroscopy, and by single crystal X-ray structure determination. The bulk structure of 1 is a 3-D metal-organic framework held together by intermetallic linkages across oxalate and aqua oxygen bridgings. Thermal analyses of 1 show significant weight losses corresponding to water molecules (lattice and coordinated), followed by the decomposition of the network.

\section{Keywords}

Tris(0xalato)Ferrate(III) Anion, Bimetallic Complex Polymer, Crystal Structure, Thermal Stability

\section{Introduction}

During the last decades, the self-assembly via metal-ligand coordination bonding approach has been demonstrated to be a useful method for the design and construction of new advanced materials that are needed to foster

${ }^{*}$ Corresponding author. 
emerging technologies [1] [2]. Compounds of interest in this context include optically active systems [3] [4], polymeric microporous open frameworks [5] and, most importantly, molecular magnets [3] [4] [6]-[8]. In this respect, the tris(oxalato)metalate(III) anions are suitable for building multifunctional properties in a molecular lattice [9]-[11].

It is well-known that the numerous donor sites of the flexible oxalato ligand grant it a significant versatility regarding the possible metal complexes it can form. Following the strategy of utilizing transition metals with versatile multidentate ligands like oxalate dianion, we recently synthesized the first 3-D polymeric salt, $\left\{\mathrm{Ba}_{6}\left(\mathrm{H}_{2} \mathrm{O}\right)_{17}\left[\mathrm{Cr}\left(\mathrm{C}_{2} \mathrm{O}_{4}\right)_{3}\right]_{4}\right\} \cdot 7 \mathrm{H}_{2} \mathrm{O}$ [12], with the ionic ratio of $3 \mathrm{Ba}^{\mathrm{II}}$ vs. $2 \mathrm{Cr}^{\mathrm{III}}$. This compound has proven to be a useful precursor for the synthesis of highly versatile complex salts with the unprecedented potential of accumulating within a single system a whole set of relevant functionalities, such as nanoscale structural features, extended hydrogen bonding, magnetic interactions [13]-[15]. Moreover, it has received great attention in the field of materials science among other reasons for its use as a convenient route for the preparation of technologically important metallic composite oxides [16].

In order to extend this family of barium(II)/metal(III)-oxalate complex salts, we now describe the synthesis, crystal structure, and thermal behavior of the new salt, $\left\{\mathrm{Ba}_{6}\left(\mathrm{H}_{2} \mathrm{O}\right)_{17}\left[\mathrm{Fe}\left(\mathrm{C}_{2} \mathrm{O}_{4}\right)_{3}\right]_{4}\right\} \cdot 7 \mathrm{H}_{2} \mathrm{O}$, which turns out to be the iron(III) analog of the previously well-characterized barium(II)/chromium(III)-oxalate polymer [12], where chromium(III) ions are replaced by iron(III) ions.

\section{Experimental}

\subsection{Materials and Measurements}

All the chemicals used were commercial grade materials. They were procured from Prolabo and Merck. The reagents were used without further purification. All reactions were carried out in distilled water as the solvent. Elemental analysis for carbon and hydrogen was performed on a Vario EL (Heraeus) CHNS analyzer. The infrared spectrum was recorded on a Perkin-Elmer (System 2000) FT-IR spectrometer with a pressed KBr pellet in the scan range $4000-400 \mathrm{~cm}^{-1}$. Thermal analyses (TGA and TDA) were performed with a Mettler Toledo TGA/SDTA 851 thermal analyzer. The powdered sample (ca. $15 \mathrm{mg}$ ) was heated from $25^{\circ} \mathrm{C}$ to $600^{\circ} \mathrm{C}$ with a rate of $10^{\circ} \mathrm{C} / \mathrm{min}$ in dry nitrogen gas flowing at $60 \mathrm{~mL} / \mathrm{min}$. The melting point was taken with an Electrothermal 9100 apparatus. Three capillary tubes were filled with a powder sample and lodged in a heating closure.

\subsection{Synthesis of $\left\{\mathrm{Ba}_{6}\left(\mathrm{H}_{2} \mathrm{O}\right)_{17}\left[\mathrm{Fe}\left(\mathrm{C}_{2} \mathrm{O}_{4}\right)_{3}\right]_{4}\right\} \cdot 7 \mathrm{H}_{2} \mathrm{O}$}

$\mathrm{Fe}\left(\mathrm{NO}_{3}\right)_{3} \cdot 9 \mathrm{H}_{2} \mathrm{O}(0.404 \mathrm{~g}, 1 \mathrm{mmol}), \mathrm{H}_{2} \mathrm{C}_{2} \mathrm{O}_{4} \cdot 2 \mathrm{H}_{2} \mathrm{O}(0.378 \mathrm{~g}, 3 \mathrm{mmol})$ and $\mathrm{Ba}\left(\mathrm{NO}_{3}\right)_{2}(0.392 \mathrm{~g}, 1.5 \mathrm{mmol})$ were dissolved in $20 \mathrm{~mL}, 10 \mathrm{~mL}$, and $10 \mathrm{~mL}$ of water respectively. The solutions of oxalic acid and barium nitrate were added in successive small portions in the solution of iron(III) nitrate. The resulting green mixture was stirred at $333 \mathrm{~K}$ for 1 hour and then filtered off. The filtrate was allowed to evaporate in darkness at room temperature. After three weeks, yellow crystals suitable for X-ray diffraction were isolated by filtration, and dried in air. Yield: 0.967 g (84.7\%). M. p.: $>240^{\circ} \mathrm{C}$. Anal. Calcd. for $\mathrm{C}_{24} \mathrm{H}_{48} \mathrm{Ba}_{6} \mathrm{Fe}_{4} \mathrm{O}_{72}\left(2536.06 \mathrm{~g} \cdot \mathrm{mol}^{-1}\right)$ : C, $11.37 ; \mathrm{H}$, 1.91\%. Found: C, 11.32; H, 1.79\%. IR (KBr disk, $\left.\mathrm{cm}^{-1}\right): v=3420$ (m), 1705 (m), 1644 (s), 1398 (s), 1271 (s), $897(w), 793$ (s), 531 (s), 477 (s).

\subsection{X-Ray Crystallography}

A yellow crystal with approximate dimensions $0.4 \times 0.3 \times 0.2 \mathrm{~mm}^{3}$ was selected under ambient conditions and attached to the tip of a nylon loop. It was mounted in a stream of cold nitrogen at 100(1) K and centered in the X-ray beam by using a video camera. The diffraction data were collected on a Bruker APEX-II CCD diffractometer and processed using the Bruker software [17]. The structure was solved by the direct method. The positions of the hydrogen atoms were calculated. The non-hydrogen atoms were refined with anisotropic displacement coefficients, and the hydrogen atoms were included in the structure factor calculation at idealized positions and were allowed to ride on the neighboring atoms with relative isotropic displacement coefficients. Structure solution and refinement were performed using the SHELX-2013 program package [18]. Crystallographic data and refinement parameters are listed in Table 1 . Selected bond distances and bond angles are given in Table 2. 


\section{Results and Discussion}

\subsection{Formation of $\left\{\mathrm{Ba}_{6}\left(\mathrm{H}_{2} \mathrm{O}\right)_{17}\left[\mathrm{Fe}\left(\mathrm{C}_{2} \mathrm{O}_{4}\right)_{3}\right]_{4}\right\} \cdot 7 \mathrm{H}_{2} \mathrm{O}$ (1)}

The title compound was prepared by the reaction in aqueous medium of $\mathrm{Ba}\left(\mathrm{NO}_{3}\right)_{2}$ with $\mathrm{H}_{2} \mathrm{C}_{2} \mathrm{O}_{4} \cdot 2 \mathrm{H}_{2} \mathrm{O}$ and $\mathrm{Fe}\left(\mathrm{NO}_{3}\right)_{3} \cdot 9 \mathrm{H}_{2} \mathrm{O}$ in the respective 1.5:3:1 molar ratio. Yellow good crystals were isolated from the filtrate with good yield. Elemental and full $\mathrm{X}$-ray structure analyses converge to support the general formulation of $\mathbf{1}$ as $\left\{\mathrm{Ba}_{6}\left(\mathrm{H}_{2} \mathrm{O}\right)_{17}\left[\mathrm{Fe}\left(\mathrm{C}_{2} \mathrm{O}_{4}\right)_{3}\right]_{4}\right\} \cdot 7 \mathrm{H}_{2} \mathrm{O}$. This unambiguously demonstrates that the single crystal used for the X-ray

Table 1. Crystal data and structure refinement parameters for compound $\mathbf{1}$.

\begin{tabular}{|c|c|}
\hline Empirical formula & $\mathrm{C}_{24} \mathrm{H}_{48} \mathrm{Ba}_{6} \mathrm{Fe}_{4} \mathrm{O}_{72}$ \\
\hline Formula weight & 2536.06 \\
\hline Temperature (K) & $100(1)$ \\
\hline Wavelength $(\AA)$ & 1.54178 \\
\hline Crystal system & triclinic \\
\hline Space group & $P \overline{1}$ \\
\hline$a(\AA)$ & $10.9539(10)$ \\
\hline$b(\AA)$ & 17.4492(15) \\
\hline$c(\AA)$ & $18.700(2)$ \\
\hline$\alpha\left(^{\circ}\right)$ & $88.868(5)$ \\
\hline$\beta\left(^{\circ}\right)$ & $86.160(7)$ \\
\hline$\gamma\left({ }^{\circ}\right)$ & $76.462(6)$ \\
\hline Volume $\left(\AA^{3}\right)$ & $3467.2(6)$ \\
\hline$Z$ & 2 \\
\hline$D_{\text {calc }}\left(\mathrm{g} / \mathrm{cm}^{3}\right)$ & 2.429 \\
\hline Absorption coefficient $\left(\mathrm{mm}^{-1}\right)$ & 33.807 \\
\hline$F(000)$ & 2416.0 \\
\hline Crystal size (mm) & $0.4 \times 0.3 \times 0.2$ \\
\hline $2 \theta$ Range for data collection $\left({ }^{\circ}\right.$ ) & $4.736-140.59$ \\
\hline Index ranges & $-13 \leq \mathrm{h} \leq 12 ;-21 \leq \mathrm{k} \leq 21 ;-22 \leq 1 \leq 22$ \\
\hline Reflections collected & 58487 \\
\hline Independent reflections $\left(R_{\text {int }}\right)$ & $12756(0.0644)$ \\
\hline Absorption correction & Semi-empirical \\
\hline Max. and min. transmission & 0.470 and 0.182 \\
\hline Refinement method & Full-matrix least squares on $F^{2}$ \\
\hline Data/restraints/parameters & $12756 / 38 / 1028$ \\
\hline Goodness-of-fit on $F^{2}$ & 1.031 \\
\hline Final $R$ indices $[I>2 \operatorname{sigma}(I)]$ & $R_{1}=0.0442, w R_{2}=0.1066$ \\
\hline$R$ indices (all data) & $R_{1}=0.0564, w R_{2}=0.1123$ \\
\hline Largest diff. peak and hole $\left(\mathrm{e} \AA^{-3}\right)$ & 2.03 and -2.64 \\
\hline
\end{tabular}


Table 2. Selected bond lengths $[\AA]$ and angles [ $\left.{ }^{\circ}\right]$ for $\mathbf{1}$.

\begin{tabular}{|c|c|c|c|}
\hline \multicolumn{2}{|c|}{ Bond Lengths } & \multicolumn{2}{|c|}{ Bond Angles } \\
\hline Fe1-O1 & $2.016(5)$ & O1-Fe1-O3 & 81.1(2) \\
\hline Fe1-O3 & 2.021(5) & O11-Fe1-O9 & $80.6(2)$ \\
\hline Fe1-O5 & $2.013(5)$ & O5-Fe1-O7 & $80.7(2)$ \\
\hline Fe1-O7 & $2.041(5)$ & O5-Fe1-O9 & $170.9(2)$ \\
\hline Fe1-O9 & $2.024(5)$ & O11-Fe1-O1 & $167.4(2)$ \\
\hline Fe1-O11 & $2.003(5)$ & O3-Fe1-O7 & $165.4(2)$ \\
\hline Fe2-O13 & $2.063(5)$ & O15-Fe2-O13 & $79.4(2)$ \\
\hline Fe2-O15 & $2.012(5)$ & O23-Fe2-O21 & 83.0(2) \\
\hline Fe2-O17 & $2.049(5)$ & O19-Fe2-O17 & $80.1(2)$ \\
\hline Fe2-O19 & $2.001(6)$ & O17-Fe2-O21 & $165.7(2)$ \\
\hline $\mathrm{Fe} 2-\mathrm{O} 21$ & $2.050(6)$ & O23-Fe2-O13 & 168.7(2) \\
\hline $\mathrm{Fe} 2-\mathrm{O} 23$ & 1.992(7) & O19-Fe2-O15 & $170.2(3)$ \\
\hline Fe3-O25 & $2.041(5)$ & O27-Fe3-O25 & $80.1(2)$ \\
\hline $\mathrm{Fe} 3-\mathrm{O} 27$ & $2.027(5)$ & O29-Fe3-O31 & $81.3(2)$ \\
\hline Fe3-O29 & $1.986(5)$ & O33-Fe3-O35 & 79.9(2) \\
\hline Fe3-O31 & $2.029(5)$ & O29-Fe3-O33 & $170.2(2)$ \\
\hline Fe3-O33 & $2.018(5)$ & O35-Fe3-O27 & $168.3(2)$ \\
\hline Fe3-O35 & $2.016(5)$ & O31-Fe3-O25 & $163.9(2)$ \\
\hline Fe4-O37 & $2.001(5)$ & O47-Fe4-O45 & $81.7(2)$ \\
\hline Fe4-O39 & $2.035(6)$ & O41-Fe4-O43 & 79.6(2) \\
\hline Fe4-O41 & $2.014(6)$ & O37-Fe4-O39 & 80.1(2) \\
\hline Fe4-O43 & $2.023(5)$ & O43-Fe4-O39 & 169.3(2) \\
\hline Fe4-O45 & $2.014(5)$ & O37-Fe4-O47 & 169.3(2) \\
\hline Fe4-O47 & $2.003(5)$ & O41-Fe4-O45 & $164.6(2)$ \\
\hline
\end{tabular}

structure determination is representative of the entire complex synthesized. Compound $\mathbf{1}$ is a light-sensitive material soluble in water. It does not melt up to $240^{\circ} \mathrm{C}$.

\subsection{Energy Dispersive X-Ray Analysis}

The EDX spectrum of $\mathbf{1}$ is shown in Figure 1. This spectrum clearly confirms the presence of chemical elements $\mathrm{C}, \mathrm{O}, \mathrm{Ba}$ and $\mathrm{Fe}$ in the crystal.

\subsection{Thermal Analysis}

The thermal behavior of 1 has been studied by thermogravimetric analysis (TGA) and differential thermal analysis (DTA) in the temperature range of $25^{\circ} \mathrm{C}$ to $600^{\circ} \mathrm{C}$ at a heating rate of $10^{\circ} \mathrm{C}$ per minute under nitrogen atmosphere. TGA and DTA curves are depicted in Figure 2. This compound shows two steps of weight loss with endothermic change between $60^{\circ} \mathrm{C}$ and $200^{\circ} \mathrm{C}$. The first step occurs from $70^{\circ} \mathrm{C}-109^{\circ} \mathrm{C}$ and this corresponds to the release of twelve $\mathrm{H}_{2} \mathrm{O}$ molecules (calc. 8.5\%, exp.: 8.6\%) and the second from $130^{\circ} \mathrm{C}-200^{\circ} \mathrm{C}$ represents the release of $10 \mathrm{H}_{2} \mathrm{O}$ molecules (calc.: 7.1\%, exp.: 7.0\%). Above $350^{\circ} \mathrm{C}$, the decomposition of the crystal network 


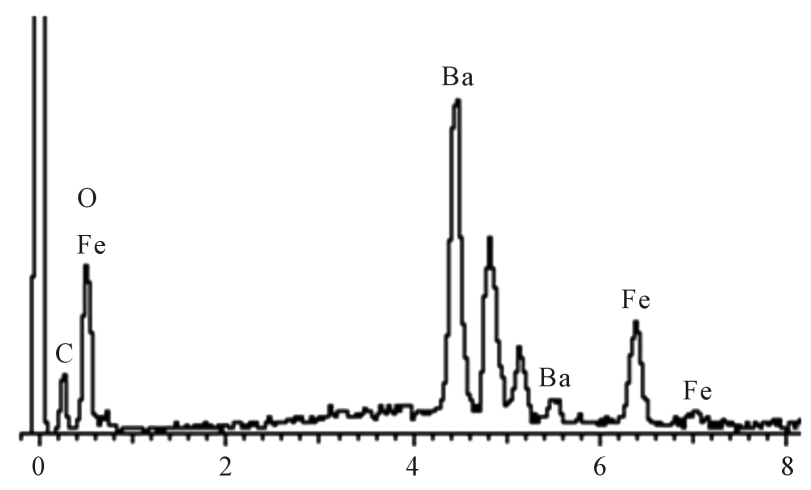

Figure 1. EDX spectrum of compound 1 showing the nature of its different chemical elements.

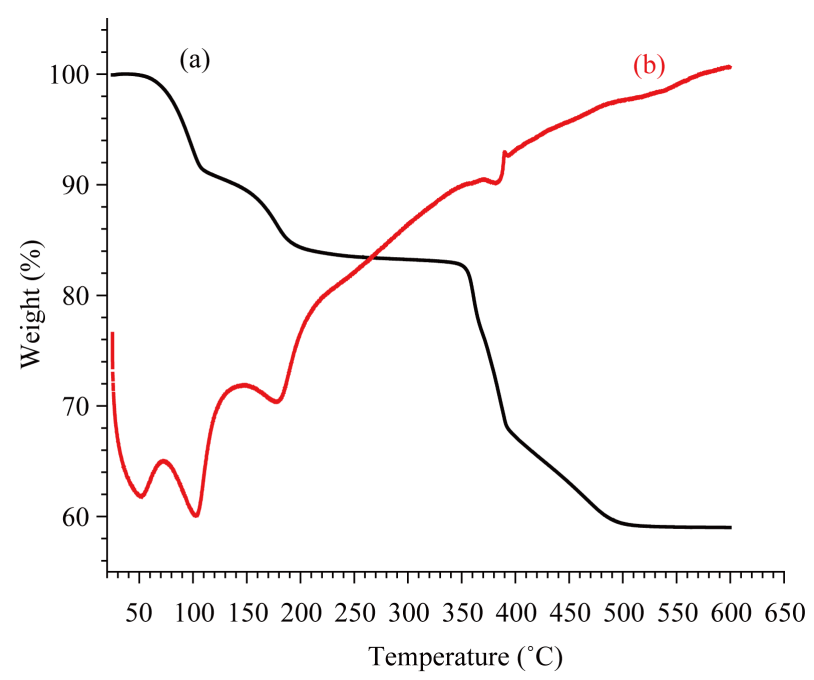

Figure 2. TGA (curve $a$ ) and DTA (curve b) of compound 1.

commences with the major weight loss in the temperature range $350^{\circ} \mathrm{C}-394^{\circ} \mathrm{C}$, which can be attributed to the release of a combined mass of $8 \mathrm{CO}_{2}+2 \mathrm{H}_{2} \mathrm{O}$ (calc. $15.3 \%$, exp.: $15.1 \%$ ) and formation of a mixture of $2\left(\mathrm{Fe}_{2} \mathrm{O}_{3} \cdot \mathrm{H}_{2} \mathrm{O}\right)$ and $\mathrm{BaC}_{2} \mathrm{O}_{4}$. Further, a small loss of weight is finally observed between $395^{\circ} \mathrm{C}-500^{\circ} \mathrm{C}$, which may be due to the release of a combined mass of $4 \mathrm{CO}_{2}+2 \mathrm{H}_{2} \mathrm{O}$ (calc. 8.4\%, exp.: 8.5\%) and formation of the residual compounds, $\mathrm{Fe}_{2} \mathrm{O}_{3}$ and $\mathrm{BaCO}_{3}$.

\subsection{Crystal Structure}

The molecular structure of $\mathbf{1}$ has been determined by X-ray study, which shows that it crystallizes in the triclinic space group $P \overline{1}$. The asymmetric unit is shown in Figure 3. Compound $\mathbf{1}$ is a 3-D polymeric structure with oxalate anions and water molecules bridging $\mathrm{Ba}^{2+}$ and $\mathrm{Fe}^{3+}$ ions. This compound is isotructural with its chromium analog $\left\{\mathrm{Ba}_{6}\left(\mathrm{H}_{2} \mathrm{O}\right)_{17}\left[\mathrm{Cr}\left(\mathrm{C}_{2} \mathrm{O}_{4}\right)_{3}\right]_{4}\right\} \cdot 7 \mathrm{H}_{2} \mathrm{O}$ characterized earlier [12]. It seems relevant, therefore, to compare the structural features of $\mathbf{1}$ with those of the chromium analog. As to be expected from structural isomorphism, the crystal data of $\mathbf{1}$ compare with the reported values (in brackets) as follows: $a=10.9539(10)$ [10.941(1)] $\AA ; b=17.4492(15)$ [17.595(1)] $\AA ; c=18.700(2)$ [18.577(1)] $\AA ; \alpha=88.868(5)$ [88.850(1) $]^{\circ} ; \beta=$ 86.160(7) [85.813(1) $]^{\circ} ; \gamma=76.462(6)$ [76.546(1)] $; V=3467.2(6)$ [3469.0(3)] $\AA^{3} ; Z=2$ [2]; $D_{x}=2.429$ [2.413] $\mathrm{g} / \mathrm{mm}^{3}$.

The constitutive ionic building blocks of the structure of $\mathbf{1}$ are the tris(oxalato)ferrate(III) anion, $\left[\mathrm{Fe}\left(\mathrm{C}_{2} \mathrm{O}_{4}\right)_{3}\right]^{3-}$, and $\mathrm{Ba}(\mathrm{II})$ cations. The anionic building unit, $\left[\mathrm{Fe}\left(\mathrm{C}_{2} \mathrm{O}_{4}\right)_{3}\right]^{3-}$, functions as a metalloligand or else as an "internetting bridge" [19]. Hence, this internetting bridge interconnects, across its twelve $\mathrm{O}$ atoms as numbered, the six independent metallic sites $\mathrm{Ba} 1, \mathrm{Ba} 2, \mathrm{Ba} 3, \mathrm{Ba} 4, \mathrm{Ba} 5$ and $\mathrm{Ba} 6$ - differently coordinated both by $\mathrm{H}_{2} \mathrm{O}$ and oxalate 
ligands-into a three-dimensional polymeric network. Each of the four independent $\mathrm{Fe}^{\mathrm{III}}$ sites is pseudo-octahedrally chelated by three oxalate $\left(\mathrm{C}_{2} \mathrm{O}_{4}^{2-}\right)$ ligands with helical orientation. Selected geometrical parameters are presented in Table 2. The Fe- $\mathrm{O}_{\text {oxalate }}$ bond lengths range from 1.986(5) $\AA$ to 2.063(5) $\AA$ and the bite angles, O-Fe-O, vary from $79.4(2)$ to $83.0(2)^{\circ}$. These bond lengths and bond angles are in good agreement with those found in other tris(oxalato)metalate(III) complexes [12] [20] [21].

The packing diagram for $\mathbf{1}$ showing hydrogen bonding interactions as viewed along the $a$-axis is shown in Figure 4. The bulk structure of $\mathbf{1}$ is consolidated by a three-dimensional network of hydrogen-bonding of the type $\mathrm{O}-\mathrm{H} \cdots \mathrm{O}$, with $\mathrm{O} \cdots \mathrm{O}$ distances ranging from 2.645(14) to 3.277(11) $\AA$ (Table 3).

\section{Conclusion}

A new complex salt, $\left\{\mathrm{Ba}_{6}\left(\mathrm{H}_{2} \mathrm{O}\right)_{17}\left[\mathrm{Fe}\left(\mathrm{C}_{2} \mathrm{O}_{4}\right)_{3}\right]_{4}\right\} \cdot 7 \mathrm{H}_{2} \mathrm{O}$ (1), obtained from aqueous solution as yellow crystals,

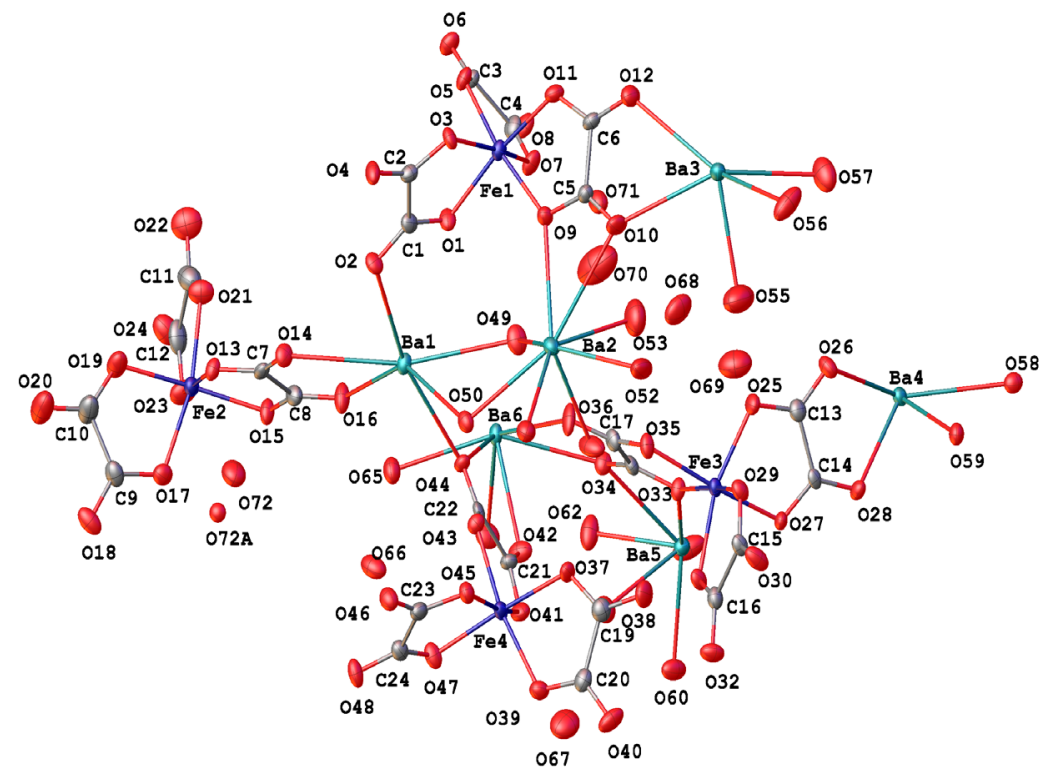

Figure 3. The asymmetric unit of compound 1. All atoms are drawn as $50 \%$ thermal probability ellipsoids. All $\mathrm{H}$ atoms are omitted for clarity.
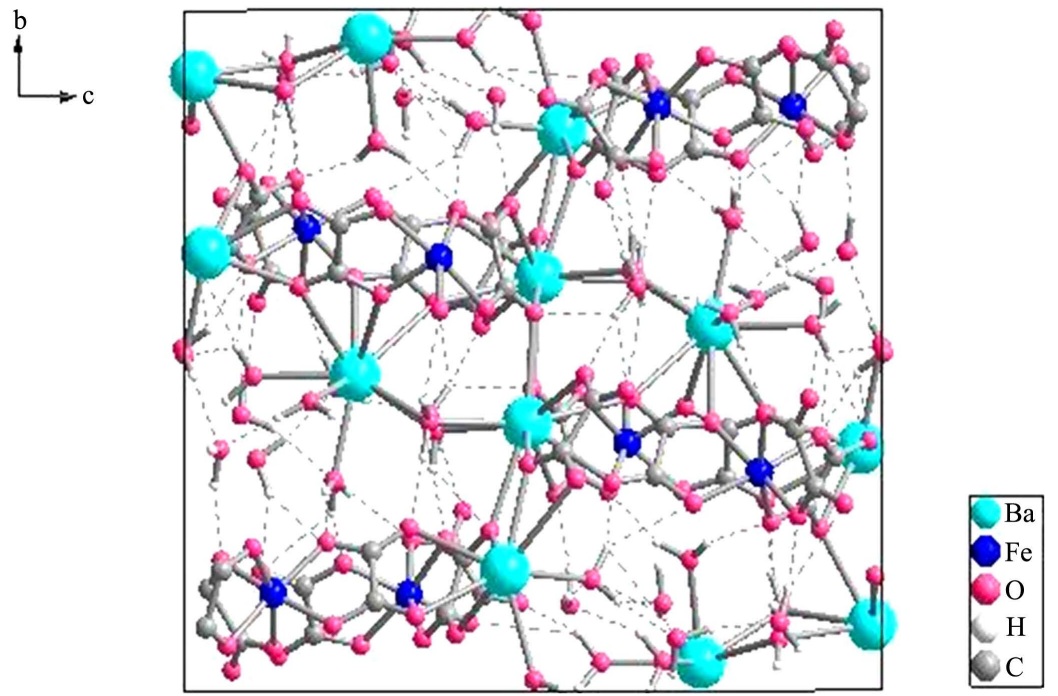

Figure 4. Packing diagram of compound 1 showing the H-bonding $\mathrm{O}-\mathrm{H} \cdots \mathrm{O}$ (dashed lines) as viewed along the $a$-axis. 
Table 3. Hydrogen bond lengths $[\AA]$ and angles $\left[{ }^{\circ}\right]$ for $\mathbf{1}$.

\begin{tabular}{|c|c|c|c|c|}
\hline $\mathrm{D}-\mathrm{H} \cdots \mathrm{A}$ & $d(\mathrm{D}-\mathrm{H})$ & $d(\mathrm{H} \cdots \mathrm{A})$ & $d(\mathrm{D} \cdots \mathrm{A})$ & $<$ (DHA) \\
\hline $\mathrm{O} 49-\mathrm{H} 49 \mathrm{~A} \cdots \mathrm{O} 70$ & 0.96 & 2.02 & $2.810(12)$ & 139.1 \\
\hline O49-H49B $\cdots$ O36 & 0.95 & 1.97 & $2.915(8)$ & 170.9 \\
\hline O50-H50B $\cdots \mathrm{O} 43$ & 0.95 & 1.81 & $2.736(7)$ & 163.3 \\
\hline O52-H52A $\cdots \mathrm{O} 69$ & 0.96 & 1.78 & $2.742(11)$ & 175.7 \\
\hline O52-H52B $\cdots \mathrm{O} 70$ & 0.96 & 1.77 & $2.645(14)$ & 148.9 \\
\hline O53-H53A $\cdots \mathrm{O}^{2} 0^{1}$ & 0.95 & 2.41 & $3.277(11)$ & 151.1 \\
\hline O53-H53A $\cdots$ O55 & 0.95 & 2.32 & 2.978(11) & 125.7 \\
\hline O55-H55A $\cdots$ O69 & 0.96 & 1.99 & $2.705(12)$ & 129.5 \\
\hline O55-Н55B $\cdots \mathrm{O} 19^{2}$ & 0.96 & 2.01 & $2.913(9)$ & 156.0 \\
\hline O60-H60A $\cdots \mathrm{O}^{3} 7^{3}$ & 0.96 & 2.01 & $2.888(8)$ & 150.2 \\
\hline O61-H61A $\cdots \mathrm{O}^{3} 6^{3}$ & 0.96 & 2.00 & $2.880(9)$ & 152.0 \\
\hline 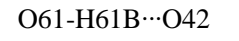 & 0.95 & 2.01 & $2.947(8)$ & 167.3 \\
\hline O62-H62A $\cdots$ O64 & 0.95 & 2.08 & $2.907(9)$ & 143.8 \\
\hline O62-H62B $\cdots \mathrm{O}^{3} 8^{3}$ & 0.96 & 1.91 & $2.792(8)$ & 152.7 \\
\hline O64-H64A $\cdots \mathrm{O} 47^{3}$ & 0.96 & 2.09 & $2.896(8)$ & 140.4 \\
\hline O64-H64B $\cdots \mathrm{O}^{3} 6^{3}$ & 0.95 & 1.94 & $2.873(9)$ & 163.7 \\
\hline O65-H65A $\cdots \mathrm{O} 16$ & 0.95 & 1.79 & $2.690(8)$ & 155.4 \\
\hline O65-H65B $\cdots \mathrm{O}^{3} 7^{3}$ & 0.96 & 1.81 & $2.746(9)$ & 163.5 \\
\hline O66-H66A $\cdots \mathrm{O} 65$ & 0.96 & 1.94 & $2.864(9)$ & 159.9 \\
\hline O67-H67A $\cdots \mathrm{O}^{3} 2^{3}$ & 0.96 & 1.91 & $2.788(11)$ & 150.5 \\
\hline 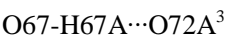 & 0.96 & 1.91 & 2.83(3) & 157.8 \\
\hline O67-H67B $\cdots \mathrm{O} 41$ & 0.95 & 1.93 & $2.769(9)$ & 146.3 \\
\hline O68-H68A $\cdots \mathrm{O} 25$ & 0.96 & 1.99 & $2.855(9)$ & 150.3 \\
\hline O69-H69A $\cdots \mathrm{O} 29$ & 0.95 & 1.91 & 2.838(9) & 164.1 \\
\hline 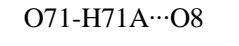 & 0.96 & 1.76 & $2.708(8)$ & 169.7 \\
\hline O72-H72A $\cdots \mathrm{O}^{3} 2^{3}$ & 0.96 & 1.92 & $2.828(9)$ & 159.0 \\
\hline O72-H72B $\cdots$ O23 & 0.95 & 1.98 & $2.928(10)$ & 171.6 \\
\hline 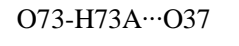 & 0.95 & 1.81 & $2.736(8)$ & 163.1 \\
\hline 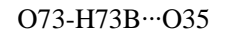 & 0.96 & 2.06 & $2.954(8)$ & 155.8 \\
\hline
\end{tabular}

Symmetry transformations used to generate equivalent atoms (D, donor; A, acceptor): ${ }^{1} 1-\mathrm{X}$, $1-\mathrm{Y}, 1-\mathrm{Z} ;{ }^{2}+\mathrm{X}, \mathrm{Y},-1+\mathrm{Z} ;{ }^{3} 1-\mathrm{X},-\mathrm{Y}, 1-\mathrm{Z}$.

has been characterized. It is the analog of the well-known barium(II)/chromuim(III)-oxalate polymer, $\left\{\mathrm{Ba}_{6}\left(\mathrm{H}_{2} \mathrm{O}\right)_{17}\left[\mathrm{Cr}\left(\mathrm{C}_{2} \mathrm{O}_{4}\right)_{3}\right]_{4}\right\} \cdot 7 \mathrm{H}_{2} \mathrm{O}$ [12], with $\mathrm{Fe}^{3+}$ in lieu of $\mathrm{Cr}^{3+}$ ions. The bulk structure of $\mathbf{1}$ is a 3-D metal-organic framework held together by intermetallic linkages across oxalate and aqua oxygen bridgings with extensive hydrogen-bonding interactions stabilizing the crystal packing. Thermal analysis of compound $\mathbf{1}$ reveals that it is stable up to ca. $80^{\circ} \mathrm{C}$. The synthesis of compound $\mathbf{1}$ provides, no doubt, a path for the preparation of further new metal(II)/meta(III)-oxalate frameworks, which may lead to the formation of a wide variety of topologies. 
Work is in progress in our laboratory on extending this interesting family of oxalate-based precursor materials.

\section{Acknowledgements}

The authors are grateful to Dr. Ilia A. Guzei, University of Wisconsin-Madison (USA), for the use of his group X-ray facilities and to Priv.-Doz. Dr. Boniface P. T. Fokwa, University of Aachen (Germany), for his help with EDX, thermal and elemental analyses.

\section{Supplementary Material}

Detailed crystallographic data in CIF format for this paper were deposited with the Cambridge Crystallographic Data Centre (CCDC-961313). The data can be obtained free of charge at www.ccdc.cam.ac.uk/conts/retrieving.html [or from Cambridge Crystallographic Data Centre (CCDC), 12 Union Road, Cambridge CB2 IEZ, UK; fax: +44 (0) 1223-336033; e-mail: deposit@ccdc.cam.ac.uk].

\section{References}

[1] Moulton, B. and Zaworotko, M.J. (2001) From Molecules to Crystal Engineering: Supramolecular Isomerism and Polymorphism in Network Solids. Chemical Reviews, 101, 1629-1658. http://dx.doi.org/10.1021/cr9900432

[2] Rao, C.N.R. and Nath, H. (2003) Inorganic Nanotubes. Dalton Transactions, 1-24. http://dx.doi.org/10.1039/b208990b

[3] Andrés, R., Brissard, M., Gruselle, M., Train, C., Vaissermann, J., Malézieux, B., Jamet, J.P. and Verdaguer, M. (2001) Rational Design of Three-Dimensional (3D) Optically Active Molecule-Based Magnets: Synthesis, Structure, Optical and Magnetic Properties of $\left\{\left[\mathrm{Ru}(\mathrm{bpy})_{3}\right]^{2+}, \mathrm{ClO}_{4}^{-},\left[\mathrm{Mn}^{\mathrm{II}} \mathrm{Cr}^{\mathrm{III}}(\mathrm{ox})_{3}\right]^{-}\right\}_{n}$ and $\left\{\left[\mathrm{Ru}(\mathrm{bpy})_{2} \mathrm{ppy}\right]^{+},\left[\mathrm{M}^{\mathrm{II}} \mathrm{Cr}^{\mathrm{III}}(\mathrm{ox})_{3}\right]^{-}\right\}_{n}$, with $\mathrm{M}^{\mathrm{II}}$ $=\mathrm{Mn}^{\mathrm{II}}, \mathrm{Ni}^{\mathrm{II}}$. X-Ray Structure of $\left\{\left[\Delta \mathrm{Ru}(\mathrm{bpy})_{3}\right]^{2+}, \mathrm{ClO}_{4}^{-},\left[\Delta \mathrm{Mn}^{\mathrm{II}} \Delta \mathrm{Cr}^{\mathrm{III}}(\mathrm{ox})_{3}\right]^{-}\right\}_{n}$ and $\left\{\left[\Lambda \mathrm{Ru}(\mathrm{bpy})_{2} \mathrm{ppy}\right]^{+}\right.$, $\left[\Lambda \mathrm{Mn}^{\mathrm{II}} \Lambda \mathrm{Cr}^{\mathrm{III}}\left(\mathrm{ox}_{3}\right]^{-}\right\}_{n}$. Inorganic Chemistry, 40, 4633-4640. http://dx.doi.org/10.1021/ic010363f

[4] Coronado, E., Galán-Mascarós, J.R., Gómez-García, C.J. and Martínez-Agudo J.M. (2001) Molecule-Based Magnets Formed by Bimetallic Three-Dimensional Oxalate Networks and Chiral Tris(bipyridyl) Complex Cations. The Series $\left[\mathrm{Z}^{\mathrm{II}}(\mathrm{bpy})_{3}\right]\left[\mathrm{ClO}_{4}\right]\left[\mathrm{M}^{\mathrm{II}} \mathrm{Cr}^{\mathrm{III}}(\mathrm{ox})_{3}\right]\left(\mathrm{Z}^{\mathrm{II}}=\mathrm{Ru}, \mathrm{Fe}, \mathrm{Co}\right.$, and Ni; $\mathrm{M}^{\mathrm{II}}=\mathrm{Mn}, \mathrm{Fe}, \mathrm{Co}, \mathrm{Ni}, \mathrm{Cu}$, and $\mathrm{Zn}$; ox = Oxalate Dianion). Inorganic Chemistry, 40, 113-120. http://dx.doi.org/10.1021/ic0008870

[5] Vaidhyanathan, R., Natarajan, S. and Rao, C.N.R. (2001) Three-Dimensional Yttrium Oxalates Possessing Large Channels. Chemistry of Materials, 13, 185-191. http://dx.doi.org/10.1021/cm000419o

[6] Lacroix, P.G., Malfant, I., Bénard, S., Yu, P., Rivière, E. and Nakatani K. (2001) Hybrid Molecular-Based Magnets Containing Organic NLO Chromophores: A Search toward an Interplay between Magnetic and NLO Behavior. Chemistry of Materials, 13, 441-449. http://dx.doi.org/10.1021/cm001177v

[7] Ferlay, S., Mallah, T., Ouahès, R., Veillet, P. and Verdaguer, M. (1995) A Room-Temperature Organometallic Magnet Based on Prussian Blue. Nature, 378, 701-703. http://dx.doi.org/10.1038/378701a0

[8] Verdaguer, M. (1996) Molecular Electronics Emerges from Molecular Magnetism. Science, 272, 698-699. http://dx.doi.org/10.1126/science.272.5262.698

[9] Hua, X., Larsson, K., Neal, T.J., Wyllie, G.R.A., Shang, M. and Lappin, A.G. (2001) Structure and Magnetic Properties of $\left[\mathrm{Cr}(\mathrm{en})_{2}(\mathrm{ox})\right]\left[\mathrm{Cr}(\mathrm{en})(\mathrm{ox})_{2}\right] \cdot 2 \mathrm{H}_{2} \mathrm{O}, \Delta-\left[\mathrm{Cr}(\mathrm{en})_{3}\right] \Delta-\left[\mathrm{Cr}(\mathrm{ox})_{3}\right]$ and $\Delta-\left[\mathrm{Co}(\mathrm{en})_{3}\right] \Delta-\left[\mathrm{Cr}(\mathrm{ox})_{3}\right]$. Inorganic Chemistry Communications, 4, 635-639. http://dx.doi.org/10.1016/S1387-7003(01)00290-8

[10] Decurtins, S., Schmalle, H.W., Schneuwly, P., Ensling, J. and Guetlich, P. (1994) A Concept for the Synthesis of 3-Dimensional Homo- and Bimetallic Oxalate-Bridged Networks $\left[\mathrm{M}_{2}(\mathrm{ox})_{3}\right]_{\mathrm{n}}$. Structural, Moessbauer, and Magnetic Studies in the Field of Molecular-Based Magnets. Journal of American Chemical Society, 116, 9521-9528. http://dx.doi.org/10.1021/ja00100a016

[11] Decurtins, S., Schmalle, H.W., Pellaux, R., Schneuwly, P. and Hauser, A. (1996) Chiral, Three-Dimensional Supramolecular Compounds: Homo- and Bimetallic Oxalate- and 1,2-Dithiooxalate-Bridged Networks. A Structural and Photophysical Study. Inorganic Chemistry, 35, 1451-1460. http://dx.doi.org/10.1021/ic950791j

[12] Bélombé, M.M., Nenwa, J., Mbiangué, Y.A., Evina-Nnanga, G., Mbomékallé, I.M., Hey-Hawkins, E., Lönnecke, P. and Majoumo, F. (2003) Unusual Aquation of $\mathrm{Ba}^{2+}$ Ions in the Solid State: Synthesis and X-Ray Structural and Spectroscopic Characterization of the Novel Polymeric Complex Salt of Empirical Formula $\left\{\mathrm{Ba}_{6}\left(\mathrm{H}_{2} \mathrm{O}\right)_{17}\left[\mathrm{Cr}(\mathrm{ox})_{3}\right]_{4}\right\} \cdot 7 \mathrm{H}_{2} \mathrm{O}$ (ox = Oxalate Dianion). Dalton Transactions, 2117-2118. http://dx.doi.org/10.1039/b302489j

[13] Bélombé, M.M., Nenwa, J., Mbiangué, Y.A., Gouet, B., Majoumo, F., Hey-Hawkins, E. and Lönnecke, P. (2009) Water-Filled Pseudo-Nanotubes in $\mathrm{Ag}_{11.60} \mathrm{H}_{0.40}\left[\mathrm{Cr}\left(\mathrm{C}_{2} \mathrm{O}_{4}\right)_{3}\right]_{4} \cdot 15 \mathrm{H}_{2} \mathrm{O}$ : Synthesis, Characterization and X-Ray Structure. Inorganica Chimica Acta, 362, 1-4. http://dx.doi.org/10.1016/j.ica.2007.03.003

[14] Bélombé, M.M., Nenwa, J., Mbiangué, Y.A., Majoumo, F., Lönnecke, P. and Hey-Hawkins, E. (2009) Hydrogen- 
Bonded Pillars of Alternating Chiral Complex Cations and Anions: 1. Synthesis, Characterization, X-Ray Structure and Thermal Stability of catena- $\left\{\left[\mathrm{Co}\left(\mathrm{H}_{2} \text { oxado }\right)_{3}\right]\left[\mathrm{Cr}\left(\mathrm{C}_{2} \mathrm{O}_{4}\right)_{3}\right] \cdot 5 \mathrm{H}_{2} \mathrm{O}\right\}$ and of Its Precursor $\left(\mathrm{H}_{3} \mathrm{Oxado}\right)\left[\mathrm{Co}\left(\mathrm{H}_{2} \mathrm{Oxado}\right)_{3}\right]-$ $\left(\mathrm{SO}_{4}\right)_{2} \cdot 2 \mathrm{H}_{2} \mathrm{O}$. Dalton Transactions, 4519-4525. http://dx.doi.org/10.1039/b818793b

[15] Mbiangué, Y.A., Nenwa, J., Bélombé, M.M., Ngoune, J. and Álvarez, E. (2012) Hydrogen-Bonded Pillars of Alternating Chiral Complex Cations and Anions: 2. Synthesis, Characterization and X-Ray Structure of Isomorphous $\mathrm{Ca}$ tena- $\left\{\left(\mathrm{H}_{3} \mathrm{O}\right)\left[\mathrm{K}\left(\mathrm{H}_{2} \mathrm{O}\right)_{3}\right] @\left[\mathrm{Ni}\left(\mathrm{H}_{2} \mathrm{Oxado}\right)_{3}\right]_{2}\left[\mathrm{Cr}\left(\mathrm{C}_{2} \mathrm{O}_{4}\right)_{3}\right]_{2} \cdot 3 \mathrm{H}_{2} \mathrm{O}\right\}$ and catena- $\left\{\left(\mathrm{H}_{3} \mathrm{O}\right)\left[\mathrm{Li}\left(\mathrm{H}_{2} \mathrm{O}\right)_{3}\right] @\left[\mathrm{Ni}_{(}\left(\mathrm{H}_{2} \mathrm{Oxado}\right)_{3}\right]_{2^{-}}\right.$ $\left.\left[\mathrm{Cr}\left(\mathrm{C}_{2} \mathrm{O}_{4}\right)_{3}\right]_{2} \cdot 3 \mathrm{H}_{2} \mathrm{O}\right\}$. Science Jet, 1, 1-9.

[16] Neo, K.E., Ong, Y.Y., Huynh, H.V. and Andy-Hor, T.S. (2006) A Single-Molecular Pathway from Heterometallic MM' $\left(\mathrm{M}=\mathrm{Ba}^{\mathrm{II}}, \mathrm{Mn}^{\mathrm{II}} ; \mathrm{M}^{\prime}=\mathrm{Cr}^{\mathrm{III}}\right)$ Oxalato Complexes to Intermetallic Composite Oxides. Journal of Materials Chemistry, 17, 1002-1006. http://dx.doi.org/10.1039/b609630a

[17] APEX-II (Version 2013. 2-0), SADABS (Version 2012-1), SAINT (Version 8.30C). (2007-2013) Bruker AXS Inc., Madison.

[18] Guzei, I.A. (2013) Internal Laboratory Computer Programs Gn.

[19] Bélombé, M.M., Nenwa, J., Tene, T.O. and Fokwa, B.P.T. (2010) Synthesis, X-Ray Structure and Thermal Behavior of Isomorphous Silver-Deficient Channel Lattice Frameworks with General Formula $\left[\left(\mathrm{Ag}_{0.25} / \mathrm{M}_{0.25}\right)\left(\mathrm{H}_{2} \mathrm{O}\right)\right] @$ $\left[\mathrm{Ag}_{2} \mathrm{M}\left(\mathrm{C}_{2} \mathrm{O}_{4}\right)_{3}\right] \cdot 4 \mathrm{H}_{2} \mathrm{O}\left(\mathrm{M}=\mathrm{Co}^{\mathrm{III}}, \mathrm{Cr}^{\mathrm{III}}\right)$. Global Journal of Inorganic Chemistry, 1, 34-41.

[20] Saritha, A., Raju, B., Ramachary, M., Raghavaiah, P. and Hussain, K.A. (2012) Synthesis, Crystal Structure and Characterization of Chiral, Three-Dimensional Anhydrous Potassium Tris(Oxalate)Ferrate(III). Physica B, 407, 4208-4213. http://dx.doi.org/10.1016/j.physb.2012.07.005

[21] Kaziro, R., Hambly, T.W., Binstead, R.A. and Beattie, J.K. (1989) Potassium Tris(oxalato)ruthenate(III). Inorganica Chimica Acta, 164, 85-91. http://dx.doi.org/10.1016/S0020-1693(00)80880-4 